\title{
ENERGY STAR Appliance Market Shares: Do They Respond to Electricity Prices, and Does It Matter?
}

\author{
Peter M. Schwarz, ${ }^{a}$ Craig A. Depken, II, ${ }^{b}$ Michael W. Herron, ${ }^{b}$ and Benjamin J. Correll ${ }^{b}$
}

\begin{abstract}
We address an apparent paradox that the market shares of four ENERGY STAR appliances in the United States do not respond to within-state changes in electricity prices. We resolve the paradox by showing that market shares do respond to between-state variation in electricity prices. We also suggest an economic explanation for the paradox through the timing of appliance purchases. Using the estimation results, we find that the four ENERGY STAR appliances reduce carbon emissions by 1.9 million megawatt-hours per year, equivalent to removing $0.1 \%$ of all U.S. vehicles, and that the addition of a $\$ 100 /$ ton $\mathrm{CO}_{2}$ price would increase these figures to 2.1 million megawatt-hours and $0.11 \%$.
\end{abstract}

Keywords: Energy efficiency, Energy Star appliances, Electricity prices, Carbon emissions, Econometric specification

https://doi.org/10.5547/01956574.42.4.psch

\section{INTRODUCTION}

In 1992, the U.S. Environmental Protection Agency (EPA) introduced the ENERGY STAR (ES) program as a voluntary labeling program with the goal of identifying and promoting energy-efficient products "to reduce greenhouse gas emissions." In 1996, EPA partnered with the U.S. Department of Energy (DOE) to provide information to consumers about appliances that save a designated amount of energy over otherwise comparable models. The ostensible goal of the program was to reduce carbon emissions by encouraging consumers to pay the higher up-front cost to purchase more energy-efficient appliances. Energy efficiency is often cited as the lowest-cost method of reducing carbon emissions. Yet its effectiveness depends upon the degree to which consumers are willing to adopt such measures.

While it is difficult to quantify the benefits and the costs of the program, especially in the absence of a counterfactual, several studies, such as Datta and Gulati (2014) and Jacobsen (2015), investigate the market share of ES appliances across the various United States. Datta and Gulati investigate how rebates on ES appliances influence market shares using data from 2000-2006; Jacobsen uses data from 2000-2009 and extends their analysis to include electricity prices, natural gas prices, and personal income.

Datta and Gulati find that rebates increase market shares of clothes washers, but not dishwashers or refrigerators; they are unable to examine air conditioners as rebates on this appliance

1. See www.energystar.gov/about/history.

a Corresponding author. Department of Economics, Belk College of Business and Energy Production and Infrastructure Center (EPIC), UNC Charlotte, Charlotte NC 28223

b Department of Economics, Belk College of Business, UNC Charlotte, Charlotte NC 28223

The Energy Journal, Vol. 42, No. 4. Copyright (C) 2021 by the IAEE. All rights reserved. 
were not available during their sample period. They do conclude that the clothes washer rebate is worthwhile by comparing the cost of $\$ 140$ per ton of $\mathrm{CO}_{2}$ emissions saved to the cost of energy efficiency savings in buildings, although it appears there are other efficiency measures available at a lower cost per ton. Jacobsen uses Datta and Gulati's rebate data and updates them through 2009, confirms their result regarding rebates, and using a fixed-effects model finds that electricity prices do not seem to correspond with changes in the market shares of ES appliances. Houde and Aldy (2017) find that appliance rebates are not very effective in that approximately $70 \%$ of consumers who file a rebate are inframarginal and that an additional $15-20 \%$ of consumers simply shifted the timing of their purchase. These customers receive payments for purchases they would have made anyway, a type of free-rider problem.

The lack of change in ES market shares in response to a change in the price of electricity is the focus of our study because if consumers do not respond to either implicit or explicit changes in the price of energy efficient appliances, ES may not be an effective way to encourage energy efficiency or carbon reductions. Such findings run counter to the law of demand and engineering estimates. According to the EIA, the residential sector in the U.S. accounts for $35 \%$ of end-use efficiency potential and will consume 29\% of baseline energy in 2020 (McKinsey \& Co., 2009). The McKinsey estimates use an engineering approach to calculate the potential for energy savings, and some critics point out that expected gains from investment in efficiency often fail to materialize because of improper installation, user error, unobserved costs, and rebound effects. Yet, the engineering estimates of the potential efficiency gains from reducing residential energy use are too large to ignore.

If consumer purchases of energy-efficient appliances do not respond to electricity prices or rebates, in defiance of the law of demand, what are possible explanations? One explanation could be the energy efficiency gap, an example of which occurs when consumers apply an above-market discount rate to energy savings and therefore underinvest in energy efficiency. ${ }^{2}$ Other explanations of the gap include market failures such as lack of information (Palmer, et al., 2012), principal-agent problems such as whether landlords or tenants are responsible for energy bills, uncertainty about future energy prices, and credit market inefficiencies. Behavioral economics explanations include consumer myopia, bounded rationality, limitations in self-control on the part of low-income consumers (Tsvetanov and Segerson, 2014), and the perception of not being able to capitalize energy efficiency into property values (Palmer, et al., 2012).

Is the energy efficiency gap large enough to lead to no price response? Do consumers not connect the electricity prices to the consumption of energy through their household appliances? Are electricity price changes sufficiently small that consumers do not find it in their best interest to purchase a potentially more expensive ES appliance $?^{3}$ Or are annual data too aggregate to capture demand responses to electricity price changes? Alternatively, might these results be generated by a specific econometric framework and the exclusion of additional relevant variables? We examine the effect of electricity prices on the market share of ES appliances including additional variables such

2. Hausman (1979) examined consumer choice among air conditioners that varied in purchase price and energy efficiency, while Dubin and McFadden (1984) looked at residential heating systems. Both papers found implied discount rates in the range of 15 to 25 percent. More recent studies such as Parry et al. (2014) have also found evidence of an elevated discount rate. It should be noted that Allcott and Greenstone (2012) cast doubt on the findings, concluding that if there is a gap, it is small. They are also critical of the McKinsey study.

3. There are two recent experimental studies, Andor et al. (2020) for Germany and Jain et al. (2021) for India, that test whether consumers respond to labelling information on energy cost savings from more efficient appliances. Both studies find a response, but acknowledge the usual caveats regarding experiments as compared to actual market responses. 
as percentage of owner-occupied housing and education levels and using a random-effects model that estimates both within-state and between-state effects. ${ }^{4}$

We have three goals in this paper. The first is to replicate in a narrow sense (see Duvendack, et al., 2017; Pesaran, 2003), the main findings of Jacobsen. We confirm that when using a fixed-effects estimator there is no statistically significant response of market shares to within-state changes in electricity prices. This presents the apparent paradox: ES appliances violate the intuition that consumers respond to higher electricity prices by increasing their demand for energy efficiency.

The second goal is to investigate another source of variation in ES appliance market shares: between-state variation. We do this in the context of Mundlak's (1978) estimator, recently reframed by Bell et al. (2019), which simultaneously estimates the within-state and between-state effects of explanatory variables using a random-effects estimator. We find that within-state effects of electricity prices remain insignificant but that market shares are positively related to between-state differences in electricity prices for three of the four ES appliances investigated.

The third goal is a calculation of the impact on carbon emissions via the market share of ES appliances of a four-cent increase in electricity prices through a $\$ 100$ per ton carbon tax. Resources for the Future (2010) estimates that an increase in residential electricity rates resulting from such a tax would be on the order of 4 cents/kWh. ${ }^{5}$ We find that the impact of the ENERGY STAR program following such a price change would be approximately 2.1 million megawatt hours per year, equivalent to removing approximately $0.11 \%$ of all U.S. vehicles from the nation's roads. The marginal effect of the carbon tax is 0.2 million megawatt hours and the equivalent of removing $0.01 \%$ of U.S. vehicles from the nation's roads.

The remainder of the paper is as follows. Section 2 describes the data and replication efforts. Section 3 describes our extension of previous studies to resolve the apparent paradox between ES market shares and electricity prices. Section 4 uses our new econometric results to simulate what might happen to US carbon emissions through ES appliances after a \$100/ton carbon tax. Section 5 offers concluding remarks.

\section{DATA DESCRIPTION AND REPLICATION}

The data used by both Datta and Gulati and Jacobsen include publicly available market shares reported by the U.S. Energy Information Administration (EIA) from 2000 through 2009 for four ES appliances: room air conditioners (AC), dishwashers (DW), clothes washers (CW), and refrigerators (RF). ${ }^{6}$ Residential electricity prices were obtained from the U.S. Energy Information Administration and represent the mean residential price for the total electric industry. ${ }^{7}$ The parameter on this variable is of the most interest for answering the primary question of whether variation in electricity rates among states explains variation in market share of ENERGY STAR appliances. We also gathered state-level per-capita income from the Bureau of Economic Analysis, and the res-

4. Using the 2009 Residential Energy Consumption Survey, Sun (2018) examines rebound effects for ES dishwashers and room air conditioners; the existence of rebound effects implies that electricity prices affect the intensity of appliance usage.

5. See Chapter 6 , especially Table 6.1 , of that report. While 4 cents $/ \mathrm{kWh}$ may appear to be a small increase, it is close to a $40 \%$ increase in the average real price of electricity during the sample period of 10.7 cents $/ \mathrm{kWh}$.

6. The U.S. DOE discontinued collecting ES market data after 2009. Houde and Aldy (2017) put together updated data privately provided to them by the USDOE as well as from a large retailer on individual customer purchases of refrigerators, clothes washers, and dishwashers, but not air conditioners.

7. See www.eia.gov/electricity/data.php. 
idential price of natural gas from the EIA. ${ }^{8}$ We obtained the unweighted state-level annual average rebates for each appliance from Datta and Gulati.

Table 1 reports the descriptive statistics of the variables utilized in the replications alongside those of Jacobsen; our sample descriptive statistics are essentially the same as those used in Jacobsen and Datta and Gulati. The market shares for ES appliances average 28.88 for clothes washers, 34.54 for room air conditioners. 29.02 for refrigerators, and 59.32 for dishwashers. In states where rebates were offered, state rebates average $\$ 51.19$ for air conditioners, $\$ 53.61$ for clothes washers, $\$ 36.45$ for dishwashers, and $\$ 38.29$ for refrigerators. Per-capita income averaged $\$ 37,670$, owner-occupied households averaged $70.22 \%$, and the percent of a state's population with a bachelor's degree averaged $26.25 \%$.

Table 1: Summary Statistics

\begin{tabular}{|c|c|c|c|c|c|c|}
\hline \multirow[b]{2}{*}{ Variable } & \multirow[b]{2}{*}{ Mean } & \multirow[b]{2}{*}{ Std. Dev } & \multirow[b]{2}{*}{ Min. } & \multirow[b]{2}{*}{ Max. } & \multicolumn{2}{|c|}{$\begin{array}{l}\text { Jacobsen Summary } \\
\text { Statistics }\end{array}$} \\
\hline & & & & & Mean & Std. Dev. \\
\hline \multicolumn{7}{|l|}{ ES market share } \\
\hline Overall & 37.95 & 22.05 & 3.25 & 99.00 & $38^{\mathrm{a}}$ & $22^{\mathrm{a}}$ \\
\hline Air Conditioner & 34.54 & 14.84 & 4.09 & 69.81 & & \\
\hline Clothes Washer & 28.88 & 13.84 & 3.26 & 60.04 & & \\
\hline Dishwasher & 59.39 & 27.01 & 3.90 & 99.00 & & \\
\hline Refrigerator & 29.02 & 8.21 & 10.54 & 57.21 & & \\
\hline \multicolumn{7}{|l|}{ Incentives (2009 Dollars) ${ }^{b}$} \\
\hline Overall ${ }^{\mathrm{c}}$ & 42.78 & 19.07 & 19.92 & 113.57 & & \\
\hline Air Conditioner & 51.19 & 1.59 & 49.82 & 53.21 & & \\
\hline Clothes Washer & 53.61 & 22.35 & 24.91 & 113.57 & & \\
\hline Dishwasher & 36.45 & 11.45 & 19.92 & 53.20 & & \\
\hline Refrigerator & 38.29 & 17.86 & 20.00 & 85.18 & & \\
\hline $\begin{array}{l}\text { Residential electricity price (cents/kWh, } 2009 \\
\text { dollars) }\end{array}$ & 10.71 & 3.29 & 6.39 & 32.38 & 10.70 & 3.29 \\
\hline Per capita income (2009 dollars) & 37,672 & 5,496 & 26,866 & 57,787 & $37,910^{\mathrm{a}}$ & $55.8^{\mathrm{a}}$ \\
\hline Pct. of households owner-occupied & 70.22 & 4.88 & 53.40 & 81.30 & & \\
\hline Pct. of population with Bachelor's degree & 26.25 & 4.63 & 15.30 & 38.20 & & \\
\hline
\end{tabular}

Notes: ${ }^{a}$ Descriptive statistics obtained from Jacobsen (2015, Table 1). Jacobsen reports market share on a scale of [0,1], we adjust to reflect our scale of $[0,100]$; Jacobsen reports incentives per $\$ 100$, we adjust to reflect our scale; Jacobsen reports income per capita in $\$ 1000$ s, we adjust to reflect our scale. ${ }^{b}$ Descriptive statistics of incentives include only those observations where incentives were non-zero. ${ }^{c}$ When we include observations where incentives were zero, we obtain an overall mean of incentives equal to 2.58 (compared to Jacobsen's mean of 2, adjusted to reflect the same units) and a standard deviation equal to 11.22 (compared to Jacobsen's standard deviation of 9, adjusted to reflect the same units).

Our replication focuses on the pooled sample results reported in Table 3 of Jacobsen. Our sample period is the same as his and we use the same variables and specifications as he does. Table 2 reports our replication efforts. We can replicate his results using our sample, including the result that within-state changes in electricity prices have no impact on ES appliance market shares. ${ }^{9}$

\section{RESOLVING THE PARADOX OF ELECTRICITY PRICES AND ES MARKET SHARES}

First, we expand the set of explanatory variables by including the percentage of a state's population with a bachelor's degree, under the assumption that a college education might make an

8. See apps.bea.gov/regional/histdata and www.eia.gov/dnav/ng/ng_pri_sum_a_EPG0_PRS_DMcf_m.htm.

9. Jacobsen uses the residential price of natural gas as an instrument for state-level electricity prices. In that case, he finds no change in ES market share response to changes in state-level electricity prices. We find the same results but do not report them here for brevity; they are available from the authors upon request. 
Table 2: Replication of Jacobsen (2015)

\begin{tabular}{|c|c|c|c|c|c|c|}
\hline \multirow[b]{2}{*}{ VARIABLES } & \multicolumn{3}{|c|}{ First Differences } & \multicolumn{3}{|c|}{ Fixed Effects } \\
\hline & (1) & (2) & (3) & (1) & (2) & (3) \\
\hline Real electricity price & $\begin{array}{l}-0.002 \\
(0.002)\end{array}$ & & $\begin{array}{c}-0.0033 \\
(0.002)\end{array}$ & $\begin{array}{l}-0.003 \\
(0.002)\end{array}$ & & $\begin{array}{l}-0.003 \\
(0.003)\end{array}$ \\
\hline Lag real electricity price & & $\begin{array}{l}-0.001 \\
(0.003)\end{array}$ & $\begin{array}{r}-0.0017 \\
(0.003)\end{array}$ & & $\begin{array}{l}-0.004 \\
(0.003)\end{array}$ & $\begin{array}{l}-0.003 \\
(0.004)\end{array}$ \\
\hline Natural gas price & $\begin{array}{c}0.002 \\
(0.001)\end{array}$ & $\begin{array}{c}0.002 \\
(0.001)\end{array}$ & $\begin{array}{l}0.0024 \\
(0.001)\end{array}$ & $\begin{array}{c}0.003 \\
(0.002)\end{array}$ & $\begin{array}{c}0.003 \\
(0.002)\end{array}$ & $\begin{array}{c}0.003 \\
(0.002)\end{array}$ \\
\hline Log(Income) & $\begin{array}{c}0.090 \\
(0.076)\end{array}$ & $\begin{array}{c}0.096 \\
(0.082)\end{array}$ & $\begin{array}{l}0.0910 \\
(0.082)\end{array}$ & $\begin{array}{c}0.122 \\
(0.081)\end{array}$ & $\begin{array}{c}0.127 \\
(0.096)\end{array}$ & $\begin{array}{c}0.122 \\
(0.096)\end{array}$ \\
\hline Observations & 1,800 & 1,600 & 1,600 & 2,000 & 1,800 & 1,800 \\
\hline R-squared & 0.781 & 0.775 & 0.775 & 0.942 & 0.938 & 0.938 \\
\hline
\end{tabular}

Notes: Robust standard errors in parentheses. Our parameters on the log of per-capita income vary slightly from Jacobsen (2015) quantitatively but not qualitatively.

individual more sensitive to problems associated with carbon emissions and that a college education might make one more sensitive to intertemporal comparisons of savings associated with an ES appliance. We also include the percentage of residences that are owner-occupied with the intuition that homeowners might be more likely to purchase an ES appliance because they anticipate internalizing all the benefits of the increased efficiency over the lifetime of the appliance (see Davis, 2010). ${ }^{10}$

Second, we extend the previous analysis by including both within-state and between-state effects in a random effects model. Following Egger and Pfaffermayr (2005), within-state changes occur from year to year and therefore reflect short-run impacts while between-state changes occur over a longer period and therefore reflect longer-run impacts. Changes in electricity prices may not influence the market share of ES appliances in the short-run (i.e., within a year) but may do so in the longer run. This more nuanced interpretation of the within and between effects is increasingly supported by other authors (see, e.g., Mundlak, 1978; Neuhaus and Kalbfleisch, 1998; Egger and Pfaffermayr, 2005; Shen et al., 2008; Dieleman and Templin, 2014; Bell et al., 2019).

With these extensions, our estimating equation becomes:

$$
M S_{j i t}=\alpha_{j 0}+\sum_{k=1}^{K} \beta_{k}\left(X_{k i t}-\bar{X}_{k i}\right)+\sum_{k=1}^{K} \delta_{k}\left(\bar{X}_{k i}\right)+v_{j i}+u_{j i t}
$$

where the dependent variable is the market share of appliance $j$, in state $i$, in year $t$ (measured on the range [0,100]), $a, \beta$, and $\delta$ are parameters to be estimated, $v_{\mathrm{ji}}$ is an appliance-state specific zero-mean error term, and $u_{j i t}$ is an appliance-state-year zero-mean error term. We assume $\operatorname{cov}\left(v_{j i}, u_{j i t}\right)=0$ for all $j$ and $t, \operatorname{cov}\left(u_{i t} u_{i s}\right)=0$ for all $\mathrm{t} \neq \mathrm{s}$, and $\operatorname{var}\left(u_{j i}\right)=\sigma_{j}^{2}$ for all $i$ and $t$. The explanatory variables included in $\mathrm{X}$ are the real electricity price, real per-capita income, the percent of a state's residences that is owner-occupied, the percent of a state's population that has a bachelor's degree, and the amount of incentives offered by the state for the particular appliance. ${ }^{11}$ The regressors measured as deviations

10. We also included the state-year energy-efficiency score created by the American Council for an Energy-Efficient Economy (ACEEE), the political orientation of the state's governorship and statehouse, the average age of the state's population, the percentage of the state's population over 65 years in age, and the average size of the household at the state level. None of these additional regressors were statistically significant and therefore we dropped them from the analysis. Levels of statistical significance for price varied depending upon the exact specification.

11. Real prices and real income calculated using the Consumer Price Index reported by the Bureau of Labor Statistics. We dropped the natural gas price variable as it was insignificant in most of our specifications. We applied Levin-Lin-Chu panel-data unit root tests with demeaning and a time trend to all appliance market shares and incentives, per-capita income, 
from state means reflect within-state effects. The regressors measured as state-specific means over the sample period reflect between-state effects.

The specification in equation (1) is motivated by several reasons. One is that it is impossible to include time-invariant variables when using a fixed-effects estimator, yet estimating a random effects model where the $v_{j i}$ are correlated with one or more regressors yields inconsistent results. Because the between-state variation in the regressors is orthogonal to the within-state variation in the regressors, by construction, Mundlak's (1978) estimator yields within-state and between-state effects simultaneously in the context of a random effects model, hence it is often called a correlated random effects model. ${ }^{12}$ Another motivation is that estimating a model that includes only within-state variation ignores the possible contribution of the between-state variation to explaining ES market shares. As shown by Dieleman and Templin (2016), ignoring the between-state variation can introduce bias and imprecision to the traditional panel estimators that include only within-state variation.

It is possible that the between-state variation in the regressors explains none of the panel-level variation in ES appliance market shares. This would occur if within-state variation alone influences ES appliance market shares. On the other hand, if between-state variation contributes to explaining the panel-level variation in ES appliance market shares, then previous studies that did not include between-state variation would have been misspecified. Thus, rather than assuming the only source of variation that might influence ES appliance market shares is within-state, this general model allows the data to reveal which sources of variation matter (this intuition follows that in Bell et al., 2019).

It is a commonplace in applied econometrics to eschew the random-effects estimator because of endogeneity concerns. However, this concern is only appropriate if the between-unit and within-unit effects are the same. Indeed, the common Hausman test of random vs. fixed effects essentially tests whether the between and within effects are the same. The intuition is that, if the between and within effects are expected to be the same, then any evidence that they are not suggests that the random-effects model is inconsistent, and one should use the fixed-effects model.

Yet, the assumption that the within and between effects are the same is itself rarely explicitly tested econometrically; most papers focus on the popular Hausman test, which has restrictive assumptions. Studies that mention the possibility of equal within and between effects tend to use economic logic as justification. For example, in the case of measuring the influence of union membership on worker wages, the between worker and within worker impacts are expected to be the same, all else equal. Yet, in the case of the market shares of energy-efficient appliances, there is no ex ante reason to expect the within-state and between-state effects to be the same.

For example, while the demand for electricity is not the same as the demand for appliances, Deryugina et al. (2017) estimate that the long-run elasticity of demand for electricity might be treble the short-run elasticity of demand. Therefore, the assumption that the within- and between-effects of electricity prices should be the same does not enjoy the same support from economic logic as the thought experiment about union membership.

Of course, a thought experiment alone does not absolve the estimation results of any bias that would arise from correlation between the error term in equation (1) and any of the included regressors. However, prudence would suggest considering the policy implications of estimation results consistent with economic logic but that require substantial bias to be overturned.

percent of home ownership, electricity prices, and percent of population with a bachelor's degree. In all cases we rejected the null of panel unit roots.

12. Bell et al. (2019) rewrite equation (1) in an alternative form to get Mundlak's model and find it more accurate to describe the between effect in Mundlak as a "contextual effect." 
Table 3: Correlated Random Effects Estimation Results

\begin{tabular}{|c|c|c|c|c|}
\hline VARIABLES & $\begin{array}{l}(1) \\
\mathrm{AC}\end{array}$ & $\begin{array}{l}(2) \\
\text { DW }\end{array}$ & $\begin{array}{l}\text { (3) } \\
\text { CW }\end{array}$ & $\begin{array}{l}(4) \\
\mathrm{RF}\end{array}$ \\
\hline \multicolumn{5}{|c|}{ Within-State Effects } \\
\hline Real Price of Electricity & $\begin{array}{c}0.076 \\
(0.740)\end{array}$ & $\begin{array}{l}-0.809 \\
(1.050)\end{array}$ & $\begin{array}{c}1.098 \\
(0.896)\end{array}$ & $\begin{array}{c}0.238 \\
(0.396)\end{array}$ \\
\hline Real Per-capita Income & $\begin{array}{c}3.136^{* * *} \\
(0.730)\end{array}$ & $\begin{array}{c}7.889 * * * \\
(1.153)\end{array}$ & $\begin{array}{c}2.491 * * * \\
(0.558)\end{array}$ & $\begin{array}{c}1.068 * * * \\
(0.282)\end{array}$ \\
\hline Incentives & $\begin{array}{c}-0.092 * * * \\
(0.027)\end{array}$ & $\begin{array}{l}0.322^{*} \\
(0.173)\end{array}$ & $\begin{array}{c}0.122 * * * \\
(0.042)\end{array}$ & $\begin{array}{c}0.085 * * \\
(0.038)\end{array}$ \\
\hline Pct. Households Owner-Occupied & $\begin{array}{c}0.504 \\
(0.570)\end{array}$ & $\begin{array}{c}3.465 * * * \\
(0.984)\end{array}$ & $\begin{array}{c}0.326 \\
(0.552)\end{array}$ & $\begin{array}{c}0.283 \\
(0.340)\end{array}$ \\
\hline Pct. With Bachelor's Degree & $\begin{array}{c}2.292 * * * \\
(0.702)\end{array}$ & $\begin{array}{c}7.216^{* * *} \\
(1.302)\end{array}$ & $\begin{array}{c}3.199 * * * \\
(0.632)\end{array}$ & $\begin{array}{c}1.426^{* * *} * \\
(0.392)\end{array}$ \\
\hline \multicolumn{5}{|c|}{ Between-State Effects } \\
\hline Real Price of Electricity & $\begin{array}{c}1.032 * * * \\
(0.333)\end{array}$ & $\begin{array}{c}0.092 \\
(0.088)\end{array}$ & $\begin{array}{c}0.796^{* *} \\
(0.340)\end{array}$ & $\begin{array}{c}0.698^{* * *} \\
(0.107)\end{array}$ \\
\hline Real Per-capita Income & $\begin{array}{c}0.066 \\
(0.220)\end{array}$ & $\begin{array}{c}0.037 \\
(0.111)\end{array}$ & $\begin{array}{c}0.147 \\
(0.235)\end{array}$ & $\begin{array}{c}0.011 \\
(0.091)\end{array}$ \\
\hline Incentives & $\begin{array}{l}-0.012 \\
(0.110)\end{array}$ & $\begin{array}{c}0.104 * * * \\
(0.037)\end{array}$ & $\begin{array}{c}0.282 * * * \\
(0.058)\end{array}$ & $\begin{array}{c}0.114 * * * \\
(0.040)\end{array}$ \\
\hline Pct. Households Owner-Occupied & $\begin{array}{c}0.429 * * \\
(0.187)\end{array}$ & $\begin{array}{c}0.053 \\
(0.058)\end{array}$ & $\begin{array}{l}0.355^{* *} \\
(0.138)\end{array}$ & $\begin{array}{c}0.237 * * * \\
(0.066)\end{array}$ \\
\hline Pct. With Bachelor's Degree & $\begin{array}{c}0.488 \\
(0.307)\end{array}$ & $\begin{array}{c}0.356^{* * *} * \\
(0.135)\end{array}$ & $\begin{array}{l}0.472^{*} \\
(0.266)\end{array}$ & $\begin{array}{l}0.192 * \\
(0.114)\end{array}$ \\
\hline Constant & $\begin{array}{l}-21.969 \\
(14.846)\end{array}$ & $\begin{array}{l}43.696 \\
(5.117)\end{array}$ & $\begin{array}{l}-23.607 \\
(12.185)\end{array}$ & $\begin{array}{r}-0.947 \\
(5.569)\end{array}$ \\
\hline $\mathrm{H}_{0}:$ Overall Significance & 146.62 & 362.74 & 246.21 & 138.92 \\
\hline $\mathrm{H}_{0}$ : No Between-State Effects & 34.36 & 4.12 & 60.89 & 53.49 \\
\hline R-squared Overall & 0.241 & 0.426 & 0.340 & 0.221 \\
\hline R-squared Within & 0.241 & 0.425 & 0.299 & 0.157 \\
\hline R-squared Between & 0.440 & 0.510 & 0.529 & 0.635 \\
\hline
\end{tabular}

Notes: The within-state and between-state effects are estimated simultaneously using Mundlak's (1978) estimator. AC indicates room air conditioner, DW indicates dishwasher, $\mathrm{CW}$ indicates clothes washer, and RF indicates refrigerator. Each specification includes 500 observations. Test of overall significance is distributed Chi-square with 10 degrees of freedom, critical value 18.39 at the five percent significance level. Test for no between-state effects is distributed Chi-square with 5 degrees of freedom, critical value 11.07 at the five percent significance level. Standard errors clustered by state reported in parentheses.

Table 3 reports the results of applying Mundlak's estimator to equation (1). ${ }^{13}$ The within-state impact of changes in real electricity price mirrors that found in Jacobsen; changes in real electricity prices are not statistically significant. However, the between-state effect of a change in real electricity price suggests that, for three of the four ES appliances, electricity price increases correspond with increases in market share over time, which is consistent with economic intuition. The one appliance for which market share does not seem to respond to electricity prices is dishwashers, which among the four appliances has the lowest amount of predicted energy savings over the life of the ES appliance.

What might explain these different results from those obtained in previous studies that focus on within estimation? One reason might be that while Jacobsen reports substantial within-state price variation over the ten-year period, there is relatively little within-state variation in electricity

13. We estimated the model described in equation (1) restricting the explanatory variables to be only those used in Jacobsen (2005). We obtained largely similar results as those obtained with the extended variable set; the within-state effect of electricity price changes remains insignificant whereas the between-state effect of electricity price changes remains significant for air conditioners and refrigerators. These results are available from the authors upon request. 
prices as compared to the between-state variation. The fixed effects estimator performs poorly when there is relatively little within-unit variation in one or more of the explanatory variables, referred to in Clark and Linzer (2015) as slow moving or sluggish. In the current context, in states that regulate electricity prices, prices tend to change slowly, and regulators try to avoid sudden price jumps. Indeed, during the 2000-2009 period the between-state variance in the real price of electricity is more than nine times that of the within-state variation (9.842 compared to 1.032). This suggests that using the within-state variance in the price of electricity to explain the within-state variance of ES market shares runs the risk of near-collinearity with the state fixed effects, which can inflate standard errors and introduce the possibility of Type II errors (see Dormann et al., 2013). This explanation is purely data driven.

A second reason might be that the between-state effects reflect bias caused by correlation between the state-level means and the error term. This could be caused by one or more variables that are correlated with the market share of ES appliances and changes in electricity prices. In order to test this concern, we estimated several instrumental variable models with which to calculate Durbin-Wu-Hausman tests for endogeneity of the state-mean prices of electricity. Specifically, we generated up to six potential instruments: the average price of electricity in each state's border states (this necessitated dropping Hawaii and Alaska), the average price of natural gas in the state, the average price of natural gas in each state's border states, the average number of heating degree days, the average number of cooling degree days, and the state's average temperature. We estimated instrumental-variable models using all six instruments and then using only the state's price of natural gas, the average price of electricity in the state's border states and the average price of natural gas in the state's border states. ${ }^{14}$ In all specifications and for all appliances we fail to reject the null hypothesis of the Durbin-Wu-Hausman test for the exogeneity of the state average price of electricity during the sample period, i.e., the between-state transformed variable. At the same time, the instruments reject underidentification and weak-instruments tests. The only indication that either set of instruments is inappropriate is in the calculation of the Hansen J-test; in all specifications other than those associated with dishwashers the J-test rejects the null of instrument comformability. However, the Hansen J-test statistic is sensitive to sample size and it is arguable that the between-effects transformed data uses a sample of 48 states which would constitute a small sample. Therefore, we feel confident that the estimation results pertaining to the between-state effects are not driven primarily by endogeneity bias. ${ }^{15}$

Notwithstanding the potential econometric explanations for the non-zero between-state effects of electricity changes, interpreting within-state effects as short-run (year-to-year) changes in ES appliance market shares and between-state effects as longer-run changes in ES appliance market shares makes the paradox less puzzling. Consumers might not find ways to use their existing refrigerator, dishwasher, or clothes washer more efficiently nor trade those appliances for a more efficient model in the months immediately after an increase in electricity prices but purchase an ES appliance when their current appliance fails or otherwise needs replacing. While appliance failures

14. Full results are available from the authors upon request and are not reported here in the interest of space.

15. Assuming only the parameter estimates of the between-state effects of electricity price changes are biased, then the effect would need to be biased by at least $42 \%$ in the case of air-conditioners, $33 \%$ in the case of clothes washers, and more than $57 \%$ in the case of refrigerators. We determined these figures by calculating the value of the estimated parameters that would render them insignificant at the conventional 5\% level, holding the standard errors constant. However, if the concern was bias in the standard errors, then they would need to increase by $74 \%$ in the case of air-conditioners, $51 \%$ in the case of clothes washers, and $134 \%$ in the case of refrigerators, in order to render the estimated parameters statistically insignificant.

It is our contention that, from a policy perspective, it is prudent to consider that the longer-run response to electricity price changes is not zero and how this response impacts the policy debate. Assuming the long-run effect is the same as the short-run effect might be counter-productive if the goal is to increase the adoption of ES appliances.

All rights reserved. Copyright (C) 2021 by the IAEE. 
and replacements might occur in years with electricity price increases and these replacement decisions might be influenced by electricity price changes in that given year, the combination might not be large enough to be statistically detectable within that given year. ${ }^{16}$

Turning to non-price variables reported in Table 3, per-capita income has a positive and statistically significant shorter-term relationship with the ES market shares for all four appliances, as reflected in the positive and statistically significant within-state parameter estimates. These results are consistent with Hausman (1979) and Dubin and McFadden (1984). On the other hand, the longer-term impacts of changes in per-capita income, reflected in the between-state parameters, are not statistically significant.

To encourage purchase of an ES appliance, many states offer rebates on the purchase price. Datta and Gulati (2014), Jacobsen (2015), and Houde and Aldy (2017) all support this intuition. In our analysis, rebates have a short-run positive impact on the market shares of three of the four ES appliances analyzed. Only in the case of air conditioners is the short-run impact of incentives negatively related to market share, but we note that air conditioner rebates were largely absent until 2007, and then only available in relatively few states. In the longer-term incentives have a positive relationship with the market share for all appliances other than air conditioners, perhaps for the same reasons.

The percent of homes that are owner-occupied has a positive and statistically significant shorter-run impact on market share for dishwashers only and a positive long-run impact on market share for all appliances other than dishwashers. This might reflect a different life cycle of dishwashers relative to the other three appliances or a different replacement process between owners and renters; perhaps owners find it easier to replace dishwashers for reasons other than failure.

The percentage of a state's population with a bachelor's degree has a positive and statistically significant impact on the market share of all four appliances in the shorter run, as reflected in statistically significant within-state impacts. The longer-run impact of the percent with a bachelor's degree is positive and weakly statistically related with the market shares of dishwashers, clothes washers, and refrigerators, but not with air conditioners.

Thus, the evidence suggests that both home ownership and college education correspond with higher market shares of ES appliances but through different mechanisms. Education might affect market shares in the short-run if education provides an immediate change in preferences for energy efficiency. ${ }^{17}$ On the other hand, home ownership does not guarantee a short-run change in preference for energy efficiency. For example, those who purchase a residence might wait several years to replace a dishwasher or a refrigerator, thereby attenuating the short-run impact of ownership on the market shares of ES appliances.

Table 3 reports several diagnostics concerning the appropriateness of the correlated random effects estimator used here. While the test of overall significance strongly rejects the null of a constant-only model for all four appliances, the test of no between-state effects fails to reject in the case of dishwashers. The test of no between-state effects is equivalent to a Hausman test against the model including only within-state variation. For three of the four appliances, the correlated random effects specification is superior to the specifications that include only within-state variation.

The last three diagnostics reported in Table 3 are various goodness of fit measures relative to the overall variation, the within-state variation, and between-state variation in the data. The overall R-squared is calculated as $\rho\left(Z_{j i t} \hat{\gamma}, M S_{j i t}\right)^{2}$, the within R-squared is calculated as

16. We acknowledge a helpful referee comment for this point.

17. Whether this relationship is because of increased numeracy or increased awareness and concern for the private and public consequences of energy consumption and energy generation is not identifiable with the aggregate data utilized here but would be a useful extension in future research. 
$\rho\left(\left(Z_{j i t}-\bar{Z}_{j i}\right) \hat{\gamma},\left(M S_{j i t}-\overline{M S}_{j i}\right)\right)^{2}$, and the between R-squared is calculated as $\rho\left(\bar{Z}_{j i} \widehat{\gamma}, \overline{M S}_{j i}\right)^{2}$, where $\rho$ indicates the correlation coefficient, $Z_{j i t}=\left[X_{j i t}, \bar{X}_{j i}\right]$, and $\hat{\gamma}=(\hat{\beta}, \hat{\delta})$ is the vector of all parameters estimated (other than the constant term). The R-squared measures ostensibly show how well the specification fits the various sources of variation in the data. For all four appliances, the between $\mathrm{R}$-square is greater than the within R-square suggesting that the specifications match between-state variation more than within-state variation.

\section{IMPLICATIONS OF A CARBON TAX AND ES MARKET SHARES}

Assuming the estimated between-state effects of electricity prices reflect the longer-run effect on ENERGY STAR market shares, we simulate how a $\$ 100$ per metric ton price on $\mathrm{CO}_{2}$ emissions translating to an increase of four cents per kilowatt-hour of electricity would influence the market share of ES appliances and reduce carbon emissions through energy savings. This estimate represents a liberal estimate of the effect a carbon price would have on the electricity market. ${ }^{18}$

From the results in Table 3, the coefficients for room air conditioners, clothes washers, and refrigerators are highly significant, with magnitudes of $1.0,0.8$, and 0.7 , respectively. The coefficient for dishwashers is 0.1 and insignificant. These coefficients correspond to longer-run elasticities of 0.32 for room air conditioners, 0.14 for clothes washers, 0.26 for refrigerators, and 0.02 for dishwashers, calculated using sample means for electricity price and market shares. Given these inelastic responses, even a large increase in electricity prices would cause only a modest increase in market shares for these appliances.

The carbon-tax price increase would correspond with an $11.95 \%$ increase in the market share for ES room air conditioners from $34.54 \%$ to $38.67 \%$, for ES refrigerators from $29.02 \%$ to $31.81 \%$, for ES clothes washers from $28.88 \%$ to $30.43 \%$, and for ES dishwashers from $59.39 \%$ to $59.76 \%$.

Table 4 shows energy savings and other relevant statistics for the four ES appliances, based on appliance calculators created by the EPA and USDOE. ${ }^{19}$ At the U.S. mean residential electricity price of 12.79 cents/kWh used as the default value in the appliance calculators, an ES unit would save the average household $\$ 7.00$ annually for refrigerators, $\$ 6.00$ for dishwashers ( $\$ 4$ for energy and \$2 for water), \$20.00 for clothes washers, and $\$ 16.00$ for room air conditioners. ${ }^{20}$ These annual savings result in savings of $\$ 73, \$ 52, \$ 192$, and $\$ 119$ for refrigerators, dishwashers, clothes washers, and room air conditioners, respectively, over the life of each unit (using an annual discount rate of $4 \%$ ), with higher savings for dishwashers and especially clothes washers if water savings are included.

We simulate a four-cent carbon tax to estimate the impact a $\$ 100$ per ton carbon tax would have on U.S. carbon emissions through its impact on ES appliances. Panel A of Table 4 reports estimates of the number of ES appliances sold in a year given the reported total number of appliances

18. A recent RFF report on carbon emissions pricing in New York by Shawhan et al. (2019) estimates that a $\$ 51 /$ ton CO2 price would add $\$ 0.02 / \mathrm{kWh}$ to the price of electricity, which would reduce our estimated $\mathrm{CO} 2$ savings by 50 percent.

19. ES appliance calculators available at www.sfwmd.gov > sites > default > files > documents. Belzer (2008) discusses the assumptions behind the EPA appliance calculator and refers to a link to the EPA's Excel spreadsheets to calculate appliance savings.

20. The numbers depend upon the appliance model chosen. For example, we chose an average sized refrigerator with side-by-side doors. For the most basic refrigerator, without an attached freezer, the additional savings for the ENERGY STAR model is $\$ 4$ per year compared to a conventional refrigerator. The data do not allow us to consider any changes in appliance efficiency levels that are inframarginal or supramarginal to the ES thresholds. 
Table 4: Simulated Annual Reduction in Carbon Emissions Before and After \$0.04/kWh Carbon Tax on Electricity

\begin{tabular}{|c|c|c|c|c|c|c|}
\hline \multicolumn{7}{|c|}{ Panel A: ES Rated Sales per Year and Total Electricity Savings Before Carbon Tax } \\
\hline & $\begin{array}{l}\text { Total Appliance } \\
\text { Sales per Year }\end{array}$ & Ave & $\begin{array}{l}\text { ge ES Market } \\
\text { Share }\end{array}$ & $\begin{array}{l}\text { ES I } \\
\text { per Y }\end{array}$ & $\begin{array}{l}\text { d Sales } \\
\text { (1000's) }\end{array}$ & $\begin{array}{l}\text { Total Electricity Saved } \\
\text { per Year (mWh) }\end{array}$ \\
\hline $\mathrm{RF}$ & $22,691,247$ & & $29.02 \%$ & & & 401,685 \\
\hline DW & $8,540,158$ & & $59.39 \%$ & & & 187,664 \\
\hline $\mathrm{CW}$ & $16,814,404$ & & $28.88 \%$ & & & 776,960 \\
\hline $\mathrm{AC}$ & $12,770,701$ & & $34.54 \%$ & & & 531,375 \\
\hline Total & $60,816,511$ & & - & & & $1,917,684$ \\
\hline \multicolumn{7}{|c|}{ Panel B: Total Electricity Savings via ES Rated Appliances After Carbon Tax } \\
\hline & \multicolumn{2}{|c|}{$\begin{array}{l}\text { Market Share After } \\
\text { Electricity Price Increase }\end{array}$} & \multicolumn{2}{|c|}{$\begin{array}{l}\text { ES Sales After Electricity } \\
\text { Price Increase (1000s) }\end{array}$} & \multicolumn{2}{|c|}{$\begin{array}{c}\text { Total Electricity Saved per Year (mWh) } \\
\text { After Electricity Price Increase }\end{array}$} \\
\hline $\mathrm{RF}$ & \multicolumn{2}{|c|}{$31.81 \%$} & \multicolumn{2}{|c|}{7,218} & \multicolumn{2}{|r|}{440,303} \\
\hline DW & \multicolumn{2}{|c|}{$59.76 \%$} & \multicolumn{2}{|c|}{5,103} & \multicolumn{2}{|r|}{188,833} \\
\hline $\mathrm{CW}$ & \multicolumn{2}{|c|}{$30.43 \%$} & \multicolumn{2}{|c|}{5,116} & \multicolumn{2}{|r|}{818,660} \\
\hline $\mathrm{AC}$ & \multicolumn{2}{|c|}{$38.67 \%$} & \multicolumn{2}{|c|}{4,938} & \multicolumn{2}{|r|}{617,303} \\
\hline Total & \multicolumn{2}{|c|}{ - } & \multicolumn{2}{|c|}{22,376} & \multicolumn{2}{|r|}{$2,065,099$} \\
\hline
\end{tabular}

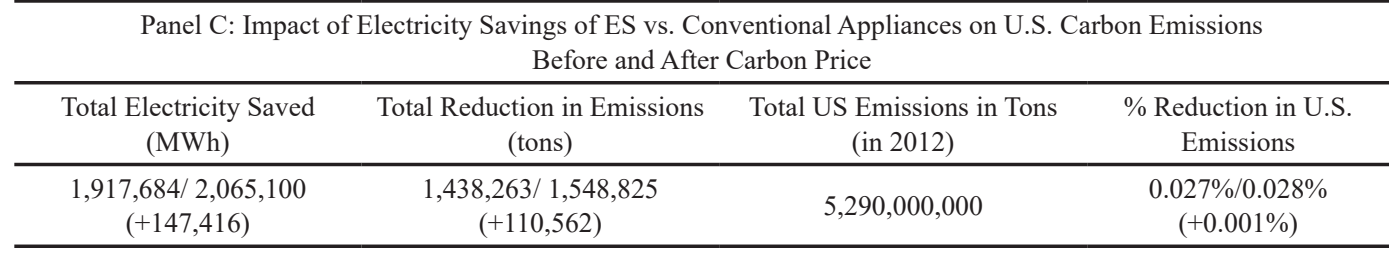

Notes: Panel A data from https://www.energystar.gov. Panel B total electricity saved per year includes $\$ 0.04 / \mathrm{kWh}$ increase in electricity prices due to a $\$ 100 /$ metric ton $\mathrm{CO}_{2}$ tax. Panel $\mathrm{C}$ reduction in emissions assumes a 0.75 metric ton reduction (approximately 1500 pounds) in $\mathrm{CO}_{2}$ emissions per MWh of electricity. First number corresponds to savings from ES appliances when there is no carbon tax. Second number corresponds to savings when the market share of ES appliances increases due to a carbon tax. The effect of the carbon tax is the difference in the two numbers, change under the Before and After numbers.

sold and the percentage of each appliance type that is ES using the average for 2000-2009. Panel $B$ reports how the four-cent carbon tax on electricity would influence market shares of ES appliances. The estimation results suggest an increase of approximately $7 \%$, or 1.45 million additional ES appliances sold per year because of the increase in electricity price. Excluding the carbon tax, the decrease in energy use from the four ES appliances would lead to a reduction in electricity usage of approximately 1.9 million megawatt hours. ${ }^{21}$ Including the carbon tax, the reduction is 2.1 million $\mathrm{MWh}$, of which 0.2 million $\mathrm{MWh}$ is due to the $4 \mathrm{cent} / \mathrm{kWh}$ carbon price. Using the approximation that each MWh of electricity generated emits 0.75 metric tons of carbon (EPA, 2017), the increased market share of ES appliances would reduce annual total carbon emissions by just over 1.4 million metric tons per year without a carbon tax and 1.55 metric tons with a carbon tax.

According to the EIA (2012), the U.S. emitted 5.290 billion metric tons in 2012. Thus, the emission reduction associated with ES appliances in the absence of a carbon tax is approximately $0.026 \%$ per year, and with the carbon tax $0.029 \%$. The annual reduction in carbon emissions is the equivalent of taking approximately 249,000 cars off the road in the absence of a carbon tax and 275,500 cars off the road after the proposed carbon tax. ${ }^{22}$ There were approximately 250 million cars

21. We used the energy savings calculators provided by the ENERGY STAR program to obtain these numbers. As of May 18,2020 , it appears to no longer be available on the Internet.

22. Based on the U.S. EPA estimate that the typical automobile has tailpipe emissions of 4.7 metric tons of carbon (Environmental Protection Agency, 2014). 
on the road in the U.S. as of 2009 , so the four ES appliances removed the equivalent of $0.1 \%$ of all cars driven, and $0.11 \%$ if we were to implement a carbon tax.

\section{CONCLUSIONS}

This study replicates a recent study about the market share of ES appliances and attempts to resolve a paradox that the market shares of ES appliances do not respond to increases in electricity prices. We successfully replicate Jacobsen (2015) both qualitatively and quantitatively. We try to resolve the paradox by extending the previous analysis by including two additional explanatory variables thought to influence the choice of purchasing an ES appliance and by simultaneously estimating within-state and between-state impacts of the explanatory variables in a random effects model.

The estimation results suggest that the market shares of the four appliances are relatively unresponsive to within-state, or shorter-run, changes in residential electricity prices. However, consistent with economic intuition, between-state, or longer-run, increases in electricity prices correspond with higher ES market shares for three of the four appliances investigated. We find that other explanatory variables have different shorter-run and longer-run impacts. Real per-capita income, the percentage of a state's population with a bachelor's degree, and incentives have greater shortrun impacts on ES market shares whereas the percentage of owner-occupied residences has a longer-term positive impact on ES market shares.

We use our estimation results to simulate the impact of the ES program on U.S. carbon emissions, and the additional effect of a $\$ 0.04$ per kilowatt-hour carbon tax on residential electricity. Even with the tax and the commensurate increase in market shares for all four ES appliances, the overall impact of the ES program on U.S. carbon emissions would be small, amounting to approximately $0.03 \%$ of total U.S. carbon emissions. The total impact of ES including a carbon tax would be equivalent to removing approximately $275,000(0.11 \%)$ of all vehicles in the United States, with $0.01 \%$ due to the carbon tax.

In 2017, there were overtures from the administration in Washington, D.C. that the ES program be cancelled (Gunther, 2017). Proponents of the proposal argued that the benefits of the program do not offset the dollar cost of the program. Proponents also argued that consumers and producers alike have built-in incentives to pursue appliance efficiency to reduce their electricity bills and therefore government intervention is not necessary (Costello 2019). Opponents of ending the program argued that the dollar costs were relatively minor and the non-monetary educational benefits were high because consumers learn more about their appliance choices and manufacturers are encouraged to improve efficiency over time. Opponents also argued that any reduction in electricity usage by the ES program had the positive externality of reduced carbon emissions. While our study does not address many of the claims on both sides, the estimation results obtained here suggest that for the four appliances investigated, the impact of the program is equivalent to the removal of $0.03 \%$ of total U.S. carbon emissions. The approach could be generalized to other ES appliances, including central air conditioning, to obtain a benefit estimate of the entire ES program.

Finally, threshold effects might exist in the decision to purchase an ES appliance. That is, if electricity prices were to rise above a psychologically important level, their effect on market share of ES appliances could become nonlinear thereby increasing the net impact of the program on emissions. This possibility is a topic for future theoretical and empirical research. 


\section{ACKNOWLEDGMENTS}

The UNC Charlotte Energy Production and Infrastructure Center (EPIC) funded the participation of Ben Correll through an undergraduate research assistantship. EPIC and the Charlotte Research Institute provided travel support. We received useful comments from Anna Sahari, Souvik Datta, and other participants at the European Association of Environmental and Resource Economics, Helsinki, Finland, June 2015; participants at the International Association of Energy Economists, North American meeting, Pittsburgh, PA, October 2015; the Hellenic Association of Energy Economics in Athens, Greece, May 2017; Southern Economic Association in Tampa, FL, November 2017; and participants at a November 2018 seminar at Henan University, Kaifeng, China. We also thank Mark Curtis for his comments.

\section{REFERENCES}

Allcott, Hunt and Michael Greenstone (2012). “Is there an energy efficiency gap?” Journal of Economic Perspectives 26(1): 3-28. https://doi.org/10.1257/jep.26.1.3.

Andor, Mark, Andreas Gerster, and Stephan Sommer (2020). "Consumer inattention, heuristic thinking and the role of energy labels.” The Energy Journal 41(1): 83-112. https://doi.org/10.5547/01956574.41.1.mand.

Association of Home Appliance Manufacturers (2001). Bulletin \#7: Major home appliance saturation and length of first ownership, Retrieved from www.aham.org.

Bell, Andrew, Malcolm Fairbrother, and Kelvyn Jones (2019). "Fixed and random effect models: making an informed choice." Quality \& Quantity 53(2): 1051-1074. https://doi.org/10.1007/s11135-018-0802-X.

Belzer, Richard (2008). Energy Star appliances: EPA's savings calculator exaggerates savings. Retrieved from neutralsource. org/archives/595.

Clark, Tom and Drew Linzer (2015). "Should I Use Fixed or Random Effects?" Political Science Research and Methods 3(2): 399-408. https://doi.org/10.1017/psrm.2014.32.

Costello, Kenneth (2019). “A Cautionary Tale About Energy Efficiency Initiatives.” Regulation 42(1): 26-29.

Datta, Souvik and Sumeet Gulati (2014). "Utility rebates for ES appliances: Are they effective?” Journal of Environmental Economics and Management 68(3): 480-506. https://doi.org/10.1016/j.jeem.2014.09.003.

Davis, Lucas. (2008). "Durable goods and residential demand for energy and water." The RAND Journal of Economics 39(2): 530-546. https://doi.org/10.1111/j.0741-6261.2008.00026.x.

Davis, Lucas. (2010). Evaluating the slow adoption of energy efficient investments: Are renters less likely to have energy efficient appliances? Working paper for the Energy Institute at HAAS (U.C. Berkeley). https://doi.org/10.3386/w16114.

Deryugina, Tatyana, Alexander MacKay, and Julian Reif, (2017). The Long-Run Dynamics of Electricity Demand: Evidence from Municipal Aggregation, No. 23483, NBER Working Papers. https://doi.org/10.3386/w23483.

Dieleman Joseph and Tara Templin (2014). "Random-effects, fixed-effects and the within-between specification for clustered data in observational health studies: a simulation study." PloS One. https://doi.org/10.1371/journal.pone.0110257.

Dormann, Carsten, Jane Elith, Sven Bacher, Carsten Buchmann, Gudrun Carl, Gabriel Carré, Jaime R. García Marquéz, Bernd Gruber, Bruno Lafourcade, Pedro J. Leitão, Tamara Münkemüller, Colin McClean, Patrick Osborne, Björn Reineking, Boris Schröder, Andrew Skidmore, Damaris Zurell, and Sven Lautenbach (2013). "Collinearity: a review of methods to deal with it and a simulation study evaluating their performance." Ecography 36(1): 27-46. https://doi.org/10.1111/ j.1600-0587.2012.07348.x.

Dubin, Jeffrey A. and Daniel L. McFadden (1984). “An econometric analysis of residential electric appliance holdings and consumption.” Econometrica 52(2): 345-362. https://doi.org/10.2307/1911493.

Duvendack, Maren, Richard Palmer-Jones, and W. Robert Reed (2017). "What Is Meant by 'Replication' and Why Does It Encounter Resistance in Economics?” American Economic Review 107(5): 46-51. https://doi.org/10.1257/aer.p20171031.

Egger, Peter and Michael Pfaffermayr (2005). "Estimating long and short run effects in static panel models." Econometric Reviews 23(3): 199-214. https://doi.org/10.1081/ETC-200028201.

ENERGY STAR (No date). Unit shipment and sales data archives, retrieved from www.energystar.gov.

Environmental Protection Agency (2017). AVERT, U.S. national weighted average $\mathrm{CO}_{2}$ marginal emission rate, year 2016 data. U.S. Environmental Protection Agency, Washington, DC. 
Frondel, Manuela and Colin Vance (2010). "Fixed, random, or something in between? A variant of Hausman's specification test for panel data estimators." Economics Letters 107(3): 327-329. https://doi.org/10.1016/j.econlet.2010.02.007.

Frondel, Manuel and Colin Vance (2011). Future pain at the diesel pump? Potential effects of the European commission's energy taxation proposal. Ruhr Economic Papers, Bochum, Germany. https://doi.org/10.2139/ssrn.1923594.

Gillingham, Kenneth (2014). "Bridging the energy efficiency gap: Policy insights from economic theory and empirical evidence." Review of Environmental Economics and Policy 8(1): 18-38. https://doi.org/10.1093/reep/ret021.

Gunther, Marc (2017). Killing ES, A popular program lands on the Trump hit list. YaleEnvironment360, e360.yale.edu/features/killing-energy-star-a-popular-program-lands-on-the-trump-hit-list, last accessed May 18, 2020.

Hausman, Jerry (1979). "Individual discount rates and the purchase and utilization of energy-using durables." Bell Journal of Economics 10(1): 33-54. https://doi.org/10.2307/3003318.

Houde, Sébastien and Joseph E. Aldy (2017). "Consumers' response to state energy efficient appliance rebate programs." American Economic Journal: Economic Policy 9(4): 227-55. https://doi.org/10.1257/pol.20140383.

Jacobsen, Grant (2015). "Do energy prices influence investment in energy efficiency? Evidence from ES appliances.” Journal of Environmental Economics and Management 74(C): 94-106. https://doi.org/10.1016/j.jeem.2015.09.004.

Jain, Manisha, Anand Rao, and Anand Patwardhan (2021). "Energy cost information and consumer decisions: Results from a choice experiment on refrigerator purchases in India." The Energy Journal 42(2): 253-271 (pre-print; page numbers may change). https://doi.org/10.5547/01956574.42.2.mjai.

McKinsey \& Co (2009). Unlocking energy efficiency in the U.S. economy. Downloaded from www.mckinsey.com.

Mundlak, Yair (1978). "On the pooling of time series and cross section data." Econometrica 46(1): 69-85. https://doi. org/10.2307/1913646.

Neuhaus, John and Jack Kalbfleisch (1998). "Between- and Within-cluster Covariate Effects in the Analysis of Clustered Data.” Biometrics 54(2): 638-645. https://doi.org/10.2307/3109770.

Palmer, Karen, Margaret Walls, and Todd Gerarden (2012). Borrowing to save energy: An assessment of energy-efficiency financing programs. Washington, DC: Resources for the Future.

Parry, Ian, David Evans, and Wallace Oates (2014). “Are energy efficiency standards justified?” Journal of Environmental Economics and Management 67(2): 104-125. https://doi.org/10.1016/j.jeem.2013.11.003.

Pesaran, Hasem (2003). "Introducing a Replication Section." Journal of Applied Econometrics 18: 111. https://doi. org/10.1002/jae.709.

Resources for the Future and the National Energy Policy Institute (2010). Toward a New National Energy Policy: Assessing the Options. Washington, D.C.: Resources for the Future.

Shawhan, Daniel, Paul Picciano, and Karen Palmer (2019). Carbon Emissions Pricing in New York: A Dynamic, Simulation-Based Analysis. Resources for the Future Report (19-08).

Shen, Lei, Jun Shao, Soomin Park, and Mari Palta (2008). "Between- and within-cluster covariate effects and model misspecification in the analysis of clustered data." Statistica Sinica 18(2): 731-748.

Sun, Bixuan (2018). "Heterogeneous direct rebound effect: Theory and evidence from the Energy Star program." Energy Economics 69: 335-349. https://doi.org/10.1016/j.eneco.2017.11.025.

Tsventanov, Tsvetan and Kathleen Segerson (2014). "The welfare effects of energy efficiency standards when choice sets matter.” Journal of Environmental Economics and Management 66(2): 347-363. https://doi.org/10.1016/j.jeem.2013.04.006.

U.S. Bureau of Economic Analysis (n.d.) Regional Economic Accounts-Previously Published Estimates. Retrieved from apps.bea.gov.

U.S. Department of Energy (2009). Refrigerator market profile. Retrieved from apps1.eere.energy.gov.

U.S. Energy Information Administration (2012) Monthly Energy Review.

U.S. Energy Information Administration (n.d.) Independent Statistics and Analysis, Electricity, Data, Retrieved from www. eia.gov.

U.S. Energy Information Administration (n.d.) Independent Statistics and Analysis, Electricity, Data Retrieved from www. eia.gov.

U.S. Environmental Protection Agency (2014). Greenhouse gas emissions from a typical passenger vehicle, Office of Transportation and Air Quality, EPA-420-F-14-040a, May. 